\title{
Electrical Stimulation for Urinary Incontinence in Women: A Systematic Review
}

\author{
Lucas Schreiner, Thais Guimarães dos Santos, Alessandra Borba Anton de Souza, Christiana Campani \\ Nygaard, Irenio Gomes da Silva Filho
}

Gynecology Department (LS, TGS, ABAS, CCN); Institute of Geriatrics and Gerontology (IGSFilho), Pontifícia Universidade Católica do Rio Grande do Sul

\begin{abstract}
Background: Electrical stimulation is commonly recommended to treat urinary incontinence in women. It includes several techniques that can be used to improve stress, urge, and mixed symptoms. However, the magnitude of the alleged benefits is not completely established.

Objectives: To determine the effects of electrical stimulation in women with symptoms or urodynamic diagnoses of stress, urge, and mixed incontinence.

Search Strategy: Our review included articles published between January 1980 and January 2012. We used the search terms "urinary incontinence", "electrical stimulation", "intravaginal", "tibial nerve" and "neuromodulation" for studies including female patients. Selection Criteria: We evaluated randomized trials that included electrical stimulation in at least one arm of the trial, to treat women with urinary incontinence.

Data Collection and Analysis: Two reviewers independently assessed the data from the trials, for inclusion or exclusion, and methodological analysis.

Main Results: A total of 30 randomized clinical trials were included. Most of the trials involved intravaginal electrical stimulation. Intravaginal electrical stimulation showed effectiveness in treating urge urinary incontinence, but reported contradictory data regarding stress and mixed incontinence. Tibial-nerve stimulation showed promising results in randomized trials with a short follow-up period. Sacral-nerve stimulation yielded interesting results in refractory patients.

Conclusions: Tibial-nerve and intravaginal stimulation have shown effectiveness in treating urge urinary incontinence. Sacral-nerve stimulation provided benefits in refractory cases. Presently available data provide no support for the use of intravaginal electrical stimulation to treat stress urinary incontinence in women. Further randomized trials are necessary to determine the magnitude of benefits, with long-term follow-up, and the effectiveness of other electrical-stimulation therapies.
\end{abstract}

ARTICLE INFO

\section{Key words:}

Adult, Women, Electrical

Stimulation, Urinary

Incontinence

Int Braz J Urol. 2013; 39: 454-64

Submitted for publication:

April 17, 2013

Accepted after revision: July 24, 2013

\section{INTRODUCTION}

Urinary incontinence is a common health problem in the female population. It results in limitations to daily activity and quality of life $(1,2)$. About 25\% of women between 15 and 64 years old and more than $50 \%$ of those attended in geriatric clinics are incontinent (3).
The International Continence Society (ICS) defines urinary incontinence (UI) as any involuntary urine leakage. Stress urinary incontinence (SUI) is defined as involuntary leakage upon effort or exertion, or upon sneezing or coughing. Urgency urinary incontinence (UUI) is the complaint of involuntary loss of urine associated with urgency; 
and mixed (urinary) incontinence (MUI) is the complaint of involuntary loss of urine associated with urgency and also with effort or physical exertion, or upon sneezing or coughing (4).

Current guidelines recommend conservative management, defined as interventions that do not involve treatment with drugs or surgery targeted to the type of incontinence, as a first-line therapy in urinary incontinence $(5,6)$.

Electrical stimulation (ES) is a therapeutic option for patients with UI. It includes the suprapubical, transvaginal, sacral and tibial nerves $(5,7)$.

Functional ES of the muscles of the pelvic floor was originally proposed by Caldwell in 1963 to address faecal and urinary incontinence. Since then, clinical trials have reported some efficacy in treating SUI, UUI and MUI $(7,8)$. The electrodes can be implantable or not, and the electrical stimulation can be of long or short duration (9).

The exact mechanism involved in improvement of urinary symptoms through electrical stimulation is not completely understood. Reorganization of spinal reflex and regulation of cortical activity are suggested as important outcomes of electrical stimulation, which would be related to the mechanism of action of this therapy (10). The mechanism of action of ES was initially investigated in animal models, where it caused bladder relaxation by inhibiting the parasympathetic motor neurons. Other studies showed that transvaginal ES causes contractions of the pelvic floor, increasing the number of muscle fibers with rapid contraction, which are responsible for continence in situations of stress (9).

Sacral-nerve stimulation consists of implantation of a wire electrode in one of the sacral foramina, usually S3, which is then connected to a stimulator device. Usually it is used for refractory urinary incontinence and idiopathic urinary retention $(9,11)$.

Tibial nerve electrical stimulation is a peripheral non-implantable method that can be applied percutaneously with a needle or transcutaneously with a stick-on electrocardiograph-type electrode (9). It was described by Mc-Guire in 1983 (12). Tibial-nerve stimulation delivers neuromodulation to the pelvic floor through the S2-S4 junction of the sacral nerve plexus via the less invasive route of the posterior tibial nerve. This anatomical area has projections to the sacral nerve plexus, creating a feed-back loop that modulates bladder innervations (13-15).

Suprapubical electrical stimulation aims for a direct stimulation of S3 nerve roots, in order to inhibit the detrusor activity, similarly to the sacral electrical stimulation, but less invasive (16).
This systematic review assessed published randomized trials on electrical stimulation, used to treat urinary incontinence in women.

\section{MATERIALS AND METHODS}

We performed an extensive electronic systematic review, searching through the Pubmed, Embase and Lilacs databases. We used a combination of the following terms: "urinary incontinence", "electrical stimulation", "intravaginal", "tibial nerve", and "neuromodulation" in trials including female patients. This search was performed according to the PRISMA Statement (17).

Two reviewers independently assessed data from trials, for inclusion or exclusion and methodological analysis. The inclusion criteria were: randomized trials, published between January 1980 and January 2012, and patients with symptoms or urodynamic diagnosis of SUI, UUI, and MUI. Electrical stimulation was used in at least one arm of the trial, and with clearly described methodology.

We excluded trials with patients with neurological disease, a language other than English, Spanish or Portuguese, or no outcomes related to urinary incontinence (scale validation, for example). We subdivided the articles into groups according to each specific electrical stimulation therapy: intravaginal, tibial, sacral, or suprapubic. When applicable, we presented the results according incontinence types (stress, urge or mixed).

We analyzed results of each group (median and range of mean values), comparing available baseline and outcome clinical data (women's observation, quantification, clinician's observation, and quality of life). In addition we compared the control or the other study group with each electrical stimulation subgroup.

\section{RESULTS}

We initially identified 763 articles through the electronic search. We evaluated the full text of 63 publications, and selected 30 randomized trials for inclusion (Figure-1).

The studies were divided into subgroups, according to the therapy studied: 21 investigated intravaginal electrical stimulation, 6 tibial nerve, 2 sacral stimulation, and 1 suprapubic.

\section{Intravaginal Electrical Stimulation}

Twenty-one randomized trials included intravaginal electrical stimulation treatment for incontinent women. Ten of them analyzed women 
with stress urinary incontinence, nine included urge urinary incontinence, and four focused on women with mixed incontinence. Two of 21 articles analyzed included stress and urge incontinence in the same paper, but we analyzed separately each complain on the same paper.

We described the results of intravaginal therapy according to the type of incontinence.

\section{Stress Urinary Incontinence}

Ten trials to treat stress urinary incontinence were included with a total of 765 patients (18-27). Most patients in all trials were close to 50 years of age. The most important outcomes of each paper are described in Table-1.

The articles described different frequencies and durations of therapies, from twice daily to once per week in frequency, and from 6 weeks to 6 months in duration, with a wide variability in the designs.
Most articles (8/10) used $50 \mathrm{hz}$ as stimulation frequency, and intensities up to $100 \mathrm{~mA}(7 / 10)$.

The most frequent outcome measure used was subjective satisfaction, used in all papers; bladder diary was used in eight; pad test in 6; and quality-of-life questionnaires in 6 , in a total of 10 papers.

Goode et al. published the trial with the largest sample analyzing 200 patients comparing IVES, behavioral training and self help booklet. Significant improvement related to baseline was established in all groups, with no difference between groups. (18).

IVES, PFMT, Vaginal Cones and no treatment were compared in 2 trials ( 21,23). While Castro et al. observed a statistically significant reduction in the pad test, in subjects who used pelvic floor exercises, electrical stimulation, and vaginal cones compared to the control group; Bo et al. found that reduction in leakage on pad test was greater in the exercise group than in the others.

Figure 1 - Flow of articles through different phases of the systematic review.

763 articles identified through

database searching

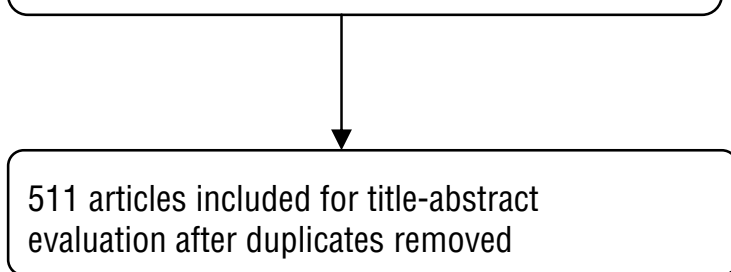

448 articles excluded based on

inclusion criteria
63 full-text articles assessed for eligibility

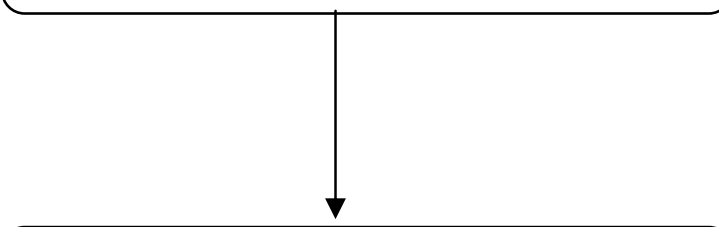

30 randomized trials included
33 full-text articles excluded

2 Full text in a language other

than English, Spanish, Portuguese

(1 Icelandic, 1 Chinese)

5 Neurological diseases

6 Electromagnetic stimulation

13 No evaluated outcomes related

to urinary incontinence

4 Not randomized

3 No urinary incontinence 


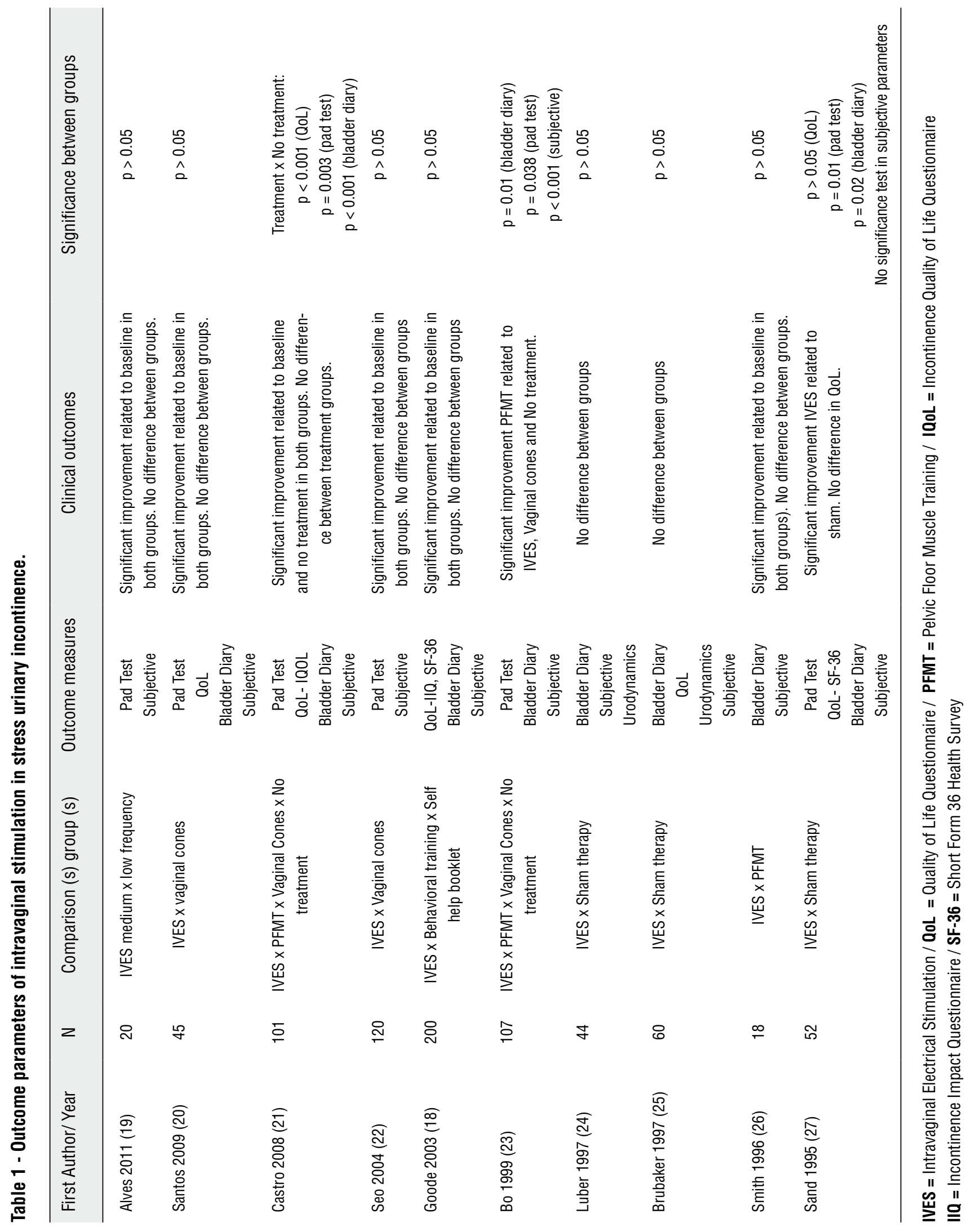


IVES versus sham therapy was evaluated in 3 trials $(24,25,27)$. Although Sand et al. found significant improvement in the active pelvic floor stimulator comparing to sham device in pad test, bladder diary and subjective self report of leakage, no difference was demonstrated in QoL.

\section{Urge Urinary Incontinence}

Nine trials to treat urge urinary incontinence were included with total of 534 patients $(25,26,28-34)$. Most patients in the trials were close to 55 years of age. The most important outcomes of each paper are described in Table-2.

Five articles (total of nine) described a frequency of twice-weekly therapy and sessions of 20 minutes. Twelve weeks was the most common duration of therapy (3/9), ranging from 4 to 16 weeks. All the studies applied an intensity of stimulation below $100 \mathrm{~mA}$, and four of them (4/9) used $10 \mathrm{hz}$ as the frequency.

The most frequent outcome measure was bladder diary, used in all papers; subjective satisfaction was used in 8; and quality-of-life questionnaires in 6, from a total of 9 papers.

Wang et al. described the largest sample with 103 patients, comparing IVES, PFMT and BAPFMT (28). IVES had the greatest subjective improvement and was the most effective of the three treatments. BAPFMT was more effective than PFMT.

Five trials compared IVES and anticholinergic drugs (26,29-32). All reported significant improvement related to baseline in both groups; however, Wang et al. found significant improvement in IVES related to Oxybutinin and placebo.

\section{Mixed Urinary Incontinence}

Four trials to treat mixed urinary incontinence were included with a total of 143 patients (35-38). Most patients in the trials were close to 50 years of age. The most important outcomes of each paper are described in Table-3.

The frequency of sessions was between twice daily and 3 times a week; the duration of therapies ranged between 7 and 12 weeks. All papers applied an intensity of stimulation below $100 \mathrm{~mA}$, and a range of 4 to $50 \mathrm{hz}$ as the frequency.

The most frequent outcome measures were subjective satisfaction (2/4), bladder diary $(2 / 4)$, and pad test (2/4). Quality-of-life questionnaire was applied in 1 paper.

Amaro et al. had the largest sample, that included 40 patients, comparing IVES and sham therapy (35). In the 60-min pad test and in the subjective satisfaction level, there was a significant reduction in both groups, with no significant difference between them.

\section{Tibial Nerve Electrical Stimulation}

Six randomized trials provided data on the use of tibial nerve stimulation for treatment of urge urinary incontinence (39-44). These trials included a total of 426 women, Peters et al. had the largest sample analyzing 174 women (39). Mean ages in the trials ranged from 40.3 to 68.9 years of age. The most important outcomes of each paper are described in Table- 4 .

The frequency of sessions was weekly in all papers, with a duration of 30 minutes for 12 weeks in most of them (4/6). Five papers applied an intensity of stimulation below $10 \mathrm{~mA}, 20 \mathrm{hz}$ as the frequency and use percutaneous technique (Urgent PC device).

The most frequent outcome measures were bladder diary (6/6), quality of life (5/6), and subjective satisfaction(4/6).

Peters et al. had the largest sample analyzing 174 women, comparing PTNS and sham therapy (39). They reported significant improvement related to baseline in both groups although significant improvement was seen in the PTNS group related to sham therapy.

Three trials compared IVES and anticholinergic drugs (41-43). All reported significant improvement related to baseline in both groups, nevertheless, two of them found significant improvement PTNS group related to medication.

\section{Sacral Stimulation}

Base on our criteria, we identified only two randomized trials evaluating sacral-nerve stimulation in urge urinary incontinence. One hundred twenty-seven women were evaluated in these papers. Both trials were done using the Interstim Device, and included patients who were refractory to previous treatments. The mean age in the papers was close to 40 years of age.

Schmidt et al. demonstrated significant improvement in urge urinary incontinence in a one-day bladder diary in the sacral-nerve group, compared to the control group $(p<0.001)$ and this benefit was sustained after 18 months (45).

Hassouni et al. demonstrated significant $(p<0.05)$ sacral stimulation benefits in quality of life (SF-36), voiding parameters, and refractory urgency frequency symptoms, compared to a standard medical treatment group (46). 
Table 2 - Outcome parameters of intravaginal stimulation in urge urinary incontinence.

\begin{tabular}{|c|c|c|c|c|c|}
\hline First Author/ Year & $\mathrm{N}$ & Comparison (s) group (s) & Outcome measures & Clincal outcomes & $\begin{array}{c}\text { Significance } \\
\text { between groups }\end{array}$ \\
\hline Franzén 2010 (29) & 61 & $\begin{array}{l}\text { IVES } \times \text { Tolterodine } 4 \mathrm{mg} \\
\text { once daily }\end{array}$ & $\begin{array}{c}\text { Bladder Diary } \\
\text { QoL- KHQ } \\
\text { Subjective }\end{array}$ & $\begin{array}{l}\text { Significant improvement } \\
\text { related to baseline in } \\
\text { both groups. No diffe- } \\
\text { rence between groups. }\end{array}$ & $p>0.05$ \\
\hline Ozdedeli 2008 (30) & 31 & $\begin{array}{c}\text { IVES x Trospium } 45 \mathrm{mg} / \\
\text { day }\end{array}$ & $\begin{array}{c}\text { Bladder Diary } \\
\text { QoL-IIQ } \\
\text { Subjective }\end{array}$ & $\begin{array}{l}\text { Significant improvement } \\
\text { related to baseline in } \\
\text { both groups. No diffe- } \\
\text { rence between groups. }\end{array}$ & $p>0.05$ \\
\hline Arruda 2007 (31) & 64 & $\begin{array}{l}\text { IVES x } 0 \text { xybutinin } 10 \mathrm{mg} / \\
\text { day } \times \text { PFMT }\end{array}$ & $\begin{array}{l}\text { Bladder Diary } \\
\text { Subjective }\end{array}$ & $\begin{array}{l}\text { Significant improvement } \\
\text { related to baseline in } \\
\text { both groups. No diffe- } \\
\text { rence between groups. }\end{array}$ & $p>0.05$ \\
\hline Wang 2006 (32) & 68 & $\begin{array}{c}\text { IVES x Oxybutinin } 7.5 \text { mg/ } \\
\text { day x Placebo }\end{array}$ & $\begin{array}{l}\text { Pad Count } \\
\text { QoL-KHQ }\end{array}$ & $\begin{array}{l}\text { Significant improve- } \\
\text { ment in IVES related to } \\
\text { Oxybutinin and placebo. } \\
\text { Significant improvement } \\
\text { related to baseline in } \\
\text { IVES and Oxybutinin. }\end{array}$ & $\begin{array}{c}\text { Pad count/24h } \\
p=0.018 \text { (x 0xy) } \\
p=0.012 \text { (x plac) } \\
\text { Qol }- \text { KHQ total } \\
p<0.001 \text { (x 0xy) } \\
p=0.006 \text { (x plac) }\end{array}$ \\
\hline Wang 2004 (28) & 103 & IVES x PFMT x BAPFMT & $\begin{array}{c}\text { QoL } \\
\text { Subjective }\end{array}$ & $\begin{array}{l}\text { Significant improvement } \\
\text { in IVES and BAPFMT } \\
\text { related to PFMT. No } \\
\text { subjective differences } \\
\text { between groups. }\end{array}$ & $\begin{array}{c}\text { Qol - KHQ total } \\
p=0.952(x \\
\text { BAPFMT) } \\
p=0.004(x \text { PFMT }) \\
\text { Subjective } \\
p=0.567 .\end{array}$ \\
\hline Berghans 2002 (33) & 68 & $\begin{array}{c}\text { IVES } x \text { PFMT x IVES+PFMT } \\
\text { x No treatment }\end{array}$ & DAI & $\begin{array}{l}\text { Significant improve- } \\
\text { ment IVES related to no } \\
\text { treatment. }\end{array}$ & $\begin{array}{l}\text { Treatment x no } \\
\text { treatment) } \\
\text { DAI } p=0.032\end{array}$ \\
\hline Yamanishi 2000 (34) & 68 & IVES x Sham therapy & $\begin{array}{c}\text { Bladder Diary } \\
\text { QoL } \\
\text { Subjective }\end{array}$ & $\begin{array}{l}\text { Significant improvement } \\
\text { IVES related to sham } \\
\text { therapy. }\end{array}$ & $\begin{array}{l}\text { Bladder diary } \\
\qquad p=0.006 \\
\text { Quality of life } \\
p=0.045\end{array}$ \\
\hline Brubaker 1997 (25) & 33 & IVES x Sham therapy & $\begin{array}{l}\text { Subjective } \\
\text { Urodynamic }\end{array}$ & $\begin{array}{l}\text { Significant improvement } \\
\text { IVES related to sham } \\
\text { therapy }\end{array}$ & $\begin{array}{l}\text { Subjective } \\
P=0.027 \\
\text { Urodynamic } \\
p=0.004\end{array}$ \\
\hline Smith $1996(26)$ & 38 & $\begin{array}{l}\text { IVES } x \text { Propantheline } \\
\text { bromide }\end{array}$ & $\begin{array}{l}\text { Bladder Diary } \\
\text { Subjective }\end{array}$ & $\begin{array}{l}\text { Significant improvement } \\
\text { related to baseline in } \\
\text { both groups. No diffe- } \\
\text { rence between groups }\end{array}$ & $p>0.05$ \\
\hline
\end{tabular}

IVES = Intravaginal Electrical Stimulation / QoL = Quality of Life Questionnaire / KHQ = Kings Health Questionnaire / IIQ = Incontinence Impact Questionnaire $/$ PFMT = Pelvic Floor Muscle Training $/ \mathbf{0 x y}=$ 0xybutinin $/$ Plac = Placebo $/$ BAPFMT $=$ Biofeedback-Assisted Pelvic Floor Muscle Training / DAI = Detrusor Activity Index 
Table 3 - Outcome parameters of intravaginal stimulation in mixed urinary incontinence.

\begin{tabular}{|c|c|c|c|c|c|}
\hline First Author/ Year & $\mathrm{N}$ & Comparison (s) group (s) & Outcome Measures & Clincal outcomes & $\begin{array}{c}\text { Significance between } \\
\text { groups }\end{array}$ \\
\hline Schmidt 2009 (36) & 32 & IVES x Biofeedback x PFMT & $\begin{array}{c}\text { Bladder Diary } \\
\text { QoL-KHQ }\end{array}$ & $\begin{array}{l}\text { Significant improvement } \\
\text { related to baseline in both } \\
\text { groups. No difference } \\
\text { between groups. }\end{array}$ & $p>0.05$ \\
\hline Amaro 2006 (35) & 40 & IVES x Sham therapy & $\begin{array}{l}\text { Pad test } \\
\text { Subjective }\end{array}$ & $\begin{array}{l}\text { Significant improvement } \\
\text { related to baseline in both } \\
\text { groups. No difference } \\
\text { between groups. }\end{array}$ & $p>0.05$ \\
\hline Barroso 2004 (37) & 36 & IVES x Placebo & Bladder Diary & $\begin{array}{l}\text { Significant improvement } \\
\text { in IVES related to baseli- } \\
\text { ne and placebo. }\end{array}$ & $p<0.001$ \\
\hline Spruijt 2003 (38) & 35 & IVES x PFMT & $\begin{array}{l}\text { Pad test } \\
\text { Subjective }\end{array}$ & $\begin{array}{l}\text { No significant } \\
\text { improvement related to } \\
\text { baseline in both groups. } \\
\text { No difference between } \\
\text { groups. }\end{array}$ & $p>0.05$ \\
\hline
\end{tabular}

IVES = Intravaginal Electrical Stimulation / PFMT = Pelvic Floor Muscle Training / Qol = Quality of Life Questionnaire

KHQ = Kings Health Questionnaire

\section{Suprapubic Stimulation}

We found only one randomized trial that used suprapubic stimulation in urinary incontinence. This trial compared three groups: suprapubic stimulation associated with pelvic floor muscle training and bladder training, suprapubic stimulation associated with pelvic-floor muscle training, and bladder training combined with trospium and trospium alone. Forty six patients were included. The stimulation group, combined or not with trospium was superior to trospium alone in quality of life $(p=0.017)$ and amount of urine leakage $(p=0.079)$ (47).

\section{DISCUSSION}

We included 30 randomized trials in this systematic review. Most of these studies used a variety of techniques for stimulation, several comparison groups, and measurements of outcomes. Therefore, it was not possible to conduct a meta-analysis.

There was no consistency between the trials in terms of types and parameters of intra- vaginal electrical-stimulation (IVES). It seems that no standard protocol or "best" methodology of IVES for the treatment of women with urinary incontinence exists. IVES offers a seemingly infinite combination of current-type waveforms, frequencies, and intensities. Some clinical trials suggest using $50 \mathrm{~Hz}$ for stress urinary incontinence, and $10-20 \mathrm{~Hz}$ for urge urinary incontinence; and that mixed symptoms should be treated according to the predominant symptom $(35,37)$.

Intravaginal electrical stimulation is a conservative treatment option described over 40 years ago. Its adverse events reported during the studies (vaginal irritation, occasional pain, vaginal infection, urinary tract infection) were not severe, and were reversible (18-20).

An argument in favour of IVES is that more than $30 \%$ of the women with stress urinary incontinence cannot manage to voluntarily contract the pelvic muscles adequately (37). Given the systemic side effects of current pharmacotherapy, IVES should be a good option for treatment in urge urinary incontinence (28). 
Table 4 - Outcome parameters of tibial nerve stimulation in urinary incontinence.

\begin{tabular}{|c|c|c|c|c|c|}
\hline First Author/ Year & $\mathrm{N}$ & Comparison (s) group (s) & Outcome measures & Clinical outcomes & $\begin{array}{c}\text { Significance } \\
\text { between groups }\end{array}$ \\
\hline Schreiner 2010 (40) & 51 & $\begin{array}{c}\text { TTNS +PFMT + BR } \times \text { PFMT } \\
+ \text { BR }\end{array}$ & $\begin{array}{c}\text { QoL- KHQ } \\
\text { Bladder Diary } \\
\text { Subjective }\end{array}$ & $\begin{array}{l}\text { Significant impro- } \\
\text { vement related to } \\
\text { baseline in both } \\
\text { groups Significant } \\
\text { improvement TTNS } \\
\text { group related to } \\
\text { PFMT + BR }\end{array}$ & $\begin{array}{c}\text { Bladder diary } \\
p<0.001 \\
\text { Subjective } \\
p=0.0017 \\
Q 0 L \\
p<0.05\end{array}$ \\
\hline Sancaktar 2010 (41) & 38 & $\begin{array}{l}\text { PTNS + Tolterodine } \times \text { Tolte- } \\
\text { rodine }\end{array}$ & $\begin{array}{c}\text { QoL- IIQ } \\
\text { Bladder Diary }\end{array}$ & $\begin{array}{l}\text { Significant impro- } \\
\text { vement related to } \\
\text { baseline in both } \\
\text { groups Significant } \\
\text { improvement PTNS } \\
\text { group related to } \\
\text { Tolterodine. }\end{array}$ & $\begin{array}{c}\text { Bladder diary } \\
\begin{array}{c}p<0.001 \\
\text { Q }\end{array} \\
p<0.05\end{array}$ \\
\hline Peters 2010 (39) & 174 & PTNS $x$ Sham therapy & $\begin{array}{c}\text { QoL- OAB-q, SF-36 } \\
\text { Bladder Diary } \\
\text { Subjective }\end{array}$ & $\begin{array}{l}\text { Significant improve- } \\
\text { ment related to ba- } \\
\text { seline in both groups } \\
\text { Significant improve- } \\
\text { ment PTNS group } \\
\text { related to Sham. }\end{array}$ & $\begin{array}{c}\text { Bladder diary } \\
p<0.001 \\
\text { Subjective } \\
p<0.001 \\
Q 0 L \\
p<0.05\end{array}$ \\
\hline Peters 2009 (42) & 97 & PTNS x Tolterodine & $\begin{array}{l}\text { QoL- OAB-q, SF-36 } \\
\text { Subjective }\end{array}$ & $\begin{array}{l}\text { Significant improve- } \\
\text { ment related to ba- } \\
\text { seline in both groups } \\
\text { Significant improve- } \\
\text { ment PTNS group } \\
\text { related to Tolterodine. } \\
\text { No differences in QoL } \\
\text { between groups. }\end{array}$ & 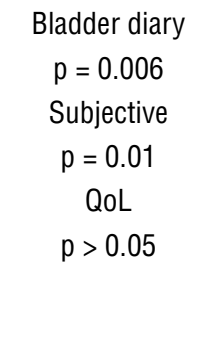 \\
\hline Karademir 2005 (43) & 38 & PTNS x PTNS + Oxibutynin & $\begin{array}{l}\text { Bladder Diary } \\
\text { Subjective }\end{array}$ & $\begin{array}{l}\text { Significant improve- } \\
\text { ment related to base- } \\
\text { line in both groups. } \\
\text { No difference between } \\
\text { groups }\end{array}$ & $p>0.05$ \\
\hline Finazzi Agró 2005 (44) & 28 & $\begin{array}{c}\text { PTNS once weekly x PTNS } 3 \\
\text { times per week }\end{array}$ & $\begin{array}{l}\text { Bladder Diary } \\
\text { QoL- I-QoL, SF-36 } \\
\text { Urodynamics } \\
\text { Subjective }\end{array}$ & $\begin{array}{l}\text { Significant improve- } \\
\text { ment related to base- } \\
\text { line in both groups. } \\
\text { No difference between } \\
\text { groups }\end{array}$ & $p>0.05$ \\
\hline
\end{tabular}

TTNS = Transcutaneous Tibial Nerve Stimulation $/$ PFMT $=$ Pelvic Floor Muscle Training $/$ BR = Bladder Retraining / QoL = Quality of Life Questionnaire $/ \mathbf{K H Q}=$ Kings Health Questionnaire / PTNS = Percutaneous Tibial Nerve Stimulation / IIQ = Incontinence Impact Questionnaire $\mathbf{O A B}-\mathbf{q}=$ Overactive Bladder Questionnaire / IQOL = Incontinence Quality of Life Questionnaire / SF-36 = Short Form 36 Health Survey 
Randomized trials evaluating intravaginal stimulation for stress urinary incontinence showed beneficial results with respect to the baseline symptoms. Only three papers compared sham vs. active therapy; two of them described no significant superiority of stimulation, which is explainable by a pelvic-floor-muscle-training effect of the sham vaginal probe in those patients, or a placebo effect in both groups.

Two studies on stress urinary incontinence showed a significant improvement when comparing stimulation with no treatment. However, in other trials, any of the treatment groups (vaginal cones, pelvic floor muscle training, behavioural training and self-help booklet) had the same or better effectiveness than intravaginal electrical stimulation in stress urinary incontinence.

Although intravaginal electrical stimulation is used worldwide, with few adverse effects, low cost, and easily available, there are not sufficient data in comparative randomized trials to characterize intravaginal electrical stimulation as an effective therapy for stress urinary incontinence. When compared with other therapies, even those that are less invasive such as pelvic-floor muscle training, it appears to provide inferior results. Therefore, the available data do not support the use of this technique in this group of patients.

In respect to intravaginal electrical stimulation to treat urge urinary incontinence, two trials compared active to sham therapy, and both showed superiority of the active therapy as evaluated by bladder diary, quality of life, urodynamics and subjective parameters. IVES showed no significant difference in effectiveness when compared with pharmacotherapy in 4 of 5 trials and it was superior in one of them (pad count an quality of life and pad count).

If we consider the relatively few adverse effects, low cost, and similar effectiveness when compared to pharmacotherapy, intravaginal electrical stimulation, according to available data, appears to be a good alternative treatment for urge urinary incontinence. Most of papers used a twice-weekly therapy, sessions of 20 minutes during twelve weeks with a $10 \mathrm{~Hz}$ frequency.

All trials (four) about intravaginal stimulation in mixed incontinence had small samples, which is a limitation for an adequate analysis of this type of incontinence. One of the trials used a sham group for comparison, and reported no significant benefit related to the baseline, or between groups. We found contradictory results about mixed incontinence. Little information was available about the predominant symptoms (urge or stress) in this subgroup of patients, and this factor may determine the results of therapy.

Among the tibial nerve stimulation trials, a large randomized study compared the technique with sham therapy, showing significant improvement in quality of life, bladder diary, and subjective outcomes. Other trials compared stimulation with pharmacotherapy (three trials), pelvic-floor muscle training plus bladder retraining (one trial) and confirmed the superiority of tibial-nerve therapy.

Tibial-nerve stimulation has shown promising initial results in large trials of urinary incontinence. However, a long follow-up period is needed to establish whether this benefit is sustained over time. We found no trials that compared the difference between percutaneous and transcutaneous techniques.

Sacral-nerve stimulation was evaluated in two randomized trials in patients with refractory urinary incontinence. This group was characterized by severe incontinence, and even so they showed significant improvement. Because this is an invasive and expensive therapy, some restrictions must be placed on its evaluation in a non-refractory group of patients. A comparison with other therapies that have been used in refractory patients (botulin toxin, for example) is necessary to determine the best option for use with refractory patients.

Very few data from randomized trials were available about suprapubic stimulation. The only paper included pelvic floor muscle training and biofeedback in both groups of suprapubic stimulation, therefore we can't attribute the improvement to electrical stimulation itself. Further studies need to be done, in order to evaluate the true value of this therapy.

Reports about electrical stimulation generally lack information on its cost-effectiveness. This is an important point, especially because in therapies with similar benefits, cost may be one of the factors to indicate the most appropriate treatment.

Any of papers reported significant complications related to the therapies, which is a point to be considered when choose the therapy to each patient.

\section{CONCLUSIONS}

Electrical stimulation is increasingly indicated in urinary incontinent patients worldwide, especially with tibial-nerve and sacral stimulation. However, few randomized trials have focused on the true benefits of this group of therapies. 
Intravaginal stimulation has proved to provide some benefit in urge urinary incontinence, but shows contradictory results in the treatment of stress and mixed incontinence. Evaluation of efficacy remains inconclusive because of the variations in stimulation parameters, and presently available data provide no support for the use of IVES to treat SUI patients.

Tibial nerve stimulation showed promising results in recent papers with few adverse effects and contraindications. However, a long follow-up period is necessary to determine whether these results persist over time. Sacral-nerve stimulation has shown interesting results in refractory patients, although comparative trials with other therapies used to treat refractory cases are needed.

\section{ABBREVIATIONS}

ICS = International Continence Society

$\mathrm{UI}=$ Urinary Incontinence

SUI $=$ Stress Urinary Incontinence

$\mathrm{UUI}=$ Urge Urinary Incontinence

MUI $=$ Mixed Urinary Incontinence

$\mathrm{ES}=$ Electrical Stimulation

IVES = Intravaginal Electrical Stimulation.

\section{CONFLICT OF INTEREST}

None declared.

\section{REFERENCES}

1. Norton $P$, Brubaker L: Urinary incontinence in women. Lancet. 2006; 367: 57-67.

2. Neumann PB, Grimmer KA, Grant RE, Gill VA: Physiotherapy for female stress urinary incontinence: a multicentre observational study. Aust N Z J Obstet Gynaecol. 2005; 45: 226-32.

3. Locher JL, Burgio KL. Epidemiology of incontinence. In Ostergard DR Bent AE editors. Urogynecology and Urodynamics: theory and practice. 4th edition. Baltimore: Willians \& Wilkins, 1996: 67-74.

4. Haylen BT, de Ridder D, Freeman RM, Swift SE, Berghmans $B$, Lee J, et al.: An International Urogynecological Association (IUGA)/International Continence Society (ICS) joint report on the terminology for female pelvic floor dysfunction. Neurourol Urodyn. 2010; 29: 4-20.

5. Thüroff JW, Abrams P, Andersson KE, Artibani W, Chapple CR, Drake MJ, et al.: EAU guidelines on urinary incontinence. Eur Urol. 2011; 59: 387-400.

6. National Institute for Clinical Excellence, NICE: Urinary incontinence: the management of urinary incontinence in women. Clinical Guideline. 2006; 40. Available at www.nice.org.uk.

7. Borello-France D, Burgio KL: Nonsurgical treatment of urinary incontinence. Clin Obstet Gynecol. 2004; 47: 70-82.
8. Caldwell KP: The electrical control of sphincter incompetence. Lancet. 1963; 2: 174-5.

9. Yamanishi T, Kamai T, Yoshida K: Neuromodulation for the treatment of urinary incontinence. Int J Urol. 2008; 15: 665-72.

10. Apostolidis A: Neuromodulation for intractable $O A B$. Neurourol Urodyn. 2011; 30: 766-70.

11. Siddiqui NY, Wu JM, Amundsen CL: Efficacy and adverse events of sacral nerve stimulation for overactive bladder: A systematic review. Neurourol Urodyn. 2010; 29: S18-23.

12. McGuire EJ, Zhang SC, Horwinski ER, Lytton B: Treatment of motor and sensory detrusor instability by electrical stimulation. J Urol. 1983; 129: 78-9.

13. Vandoninck V, Van Balken MR, Finazzi Agró E, Petta F, Caltagirone $\mathrm{C}$, Heesakkers JP, et al.: Posterior tibial nerve stimulation in the treatment of urge incontinence. Neurourol Urodyn. 2003; 22: 17-23.

14. Cooperberg MR, Stoller ML: Percutaneous neuromodulation. Urol Clin North Am. 2005; 32: 71-8.

15. Congregado Ruiz B, Pena Outeiriño XM, Campoy Martínez $P$, León Dueñas E, Leal López A: Peripheral afferent nerve stimulation for treatment of lower urinary tract irritative symptoms. Eur Urol. 2004; 45: 65-9.

16. Bower WF, Moore KH, Adams RD, Shepherd R: A urodynamic study of surface neuromodulation versus sham in detrusor instability and sensory urgency. J Urol. 1998; 160: 2133-6.

17. Moher D, Liberati A, Tetzlaff J, Altman DG, The PRISMA Group: Preferred reporting items for systematic reviews and meta-analyses: the PRISMA statement. PLoS Med. 2009; 21: 6: e1000097.

18. Goode PS, Burgio KL, Locher JL, Roth DL, Umlauf MG, Richter $\mathrm{HE}$, et al.: Effect of behavioral training with or without pelvic floor electrical stimulation on stress incontinence in women: a randomized controlled trial. JAMA. 2003; 290: 345-52.

19. Alves PG, Nunes FR, Guirro EC: Comparison between two different neuromuscular electrical stimulation protocols for the treatment of female stress urinaryincontinence: a randomized controlled trial. Rev Bras Fisioter. 2011; 15: 393-8.

20. Santos PF, Oliveira E, Zanetti MR, Arruda RM, Sartori MG, Girão MJ, et al.: Electrical stimulation of the pelvic floor versus vaginal cone therapy for the treatment of stress urinary incontinence. Rev Bras Ginecol Obstet. 2009; 31: 447-52.

21. Castro RA, Arruda RM, Zanetti MR, Santos PD, Sartori MG, Girão MJ: Single-blind, randomized, controlled trial of pelvic floor muscle training, electrical stimulation, vaginal cones, and no activetreatment in the management of stress urinary incontinence. Clinics (Sao Paulo). 2008; 63: 465-72.

22. Seo JT, Yoon H, Kim YH: A randomized prospective study comparing new vaginal cone and FES-Biofeedback. Yonsei Med J. 2004; 45: 879-84.

23. Bø K, Talseth T, Holme I: Single blind, randomised controlled trial of pelvic floor exercises, electrical stimulation, vaginal cones, and no treatment in management of genuine stress incontinence in women. BMJ. 1999; 318: 487-93. 
24. Luber KM, Wolde-Tsadik G: Efficacy of functional electrical stimulation in treating genuine stress incontinence: a randomized clinical trial. Neurourol Urodyn. 1997; 16: 543-51.

25. Brubaker L, Benson JT, Bent A, Clark A, Shott S: Transvaginal electrical stimulation for female urinary incontinence. Am J Obstet Gynecol. 1997; 177: 536-40.

26. Smith JJ 3rd: Intravaginal stimulation randomized trial. J Urol. 1996; 155: 127-30.

27. Sand PK, Richardson DA, Staskin DR, Swift SE, Appell RA, Whitmore KE, et al.: Pelvic floor electrical stimulation in the treatment of genuine stress incontinence: a multicenter, placebo-controlled trial. Gynecol. 1995; 173: 72-9.

28. Wang AC, Wang YY, Chen MC: Single-blind, randomized trial of pelvic floor muscle training, biofeedback-assisted pelvic floor muscle training, andelectrical stimulation in the management of overactive bladder. Urology. 2004; 63: 61-6.

29. Franzén K, Johansson JE, Lauridsen I, Canelid J, Heiwall B, Nilsson K: Electrical stimulation compared with tolterodine for treatment of urge/urge incontinence amongst women-a randomizedcontrolled trial. Int Urogynecol J. 2010; 21: 1517-24.

30. Ozdedeli S, Karapolat H, Akkoc Y: Comparison of intravaginal electrical stimulation and trospium hydrochloride in women with overactive bladder syndrome: arandomized controlled study. Clin Rehabil. 2010; 24: 342-51.

31. Arruda RM, Castro RA, Sousa GC, Sartori MG, Baracat EC, Girão MJ: Prospective randomized comparison of oxybutynin, functional electrostimulation, and pelvic floor training for treatment ofdetrusor overactivity in women. Int Urogynecol J Pelvic Floor Dysfunct. 2008; 19: 1055-61.

32. Wang AC, Chih SY, Chen MC: Comparison of electric stimulation and oxybutynin chloride in management of overactive bladder with special reference tourinary urgency: a randomized placebo-controlled trial. Urology. 2006; 68: 999-1004.

33. Berghmans $B$, van Waalwijk van Doorn E, Nieman F, de Bie $R$, van den Brandt $P$, Van Kerrebroeck P: Efficacy of physical therapeutic modalities in women with proven bladder overactivity. Eur Urol. 2002; 41: 581-7.

34. Yamanishi T, Yasuda K, Sakakibara R, Hattori T, Suda S: Randomized, double-blind study of electrical stimulation for urinary incontinence due to detrusor overactivity. Urology. 2000; 55: 353-7.

35. Amaro JL, Gameiro MO, Kawano PR, Padovani CR: Intravaginal electrical stimulation: a randomized, double-blind study on the treatment of mixed urinary incontinence. Acta Obstet Gynecol Scand. 2006; 85: 619-22.

36. Schmidt AP, Sanches PR, Silva DP Jr, Ramos JG, Nohama $P$ : A new pelvic muscle trainer for the treatment of urinary incontinence. Int J Gynaecol Obstet. 2009; 105: 218-22.

37. Barroso JC, Ramos JG, Martins-Costa S, Sanches PR, Muller AF: Transvaginal electrical stimulation in the treatment of urinary incontinence. BJU Int. 2004; 93: 319-23.
38. Spruijt J, Vierhout M, Verstraeten R, Janssens J, Burger C: Vaginal electrical stimulation of the pelvic floor: a randomized feasibility study in urinary incontinent elderly women. Acta Obstet Gynecol Scand. 2003; 82: 1043-8.

39. Peters KM, Carrico DJ, Perez-Marrero RA, Khan AU, Wooldridge LS, Davis GL, et al.: Randomized trial of percutaneous tibial nerve stimulation versus Sham efficacy in the treatment of overactive bladdersyndrome: results from the SUmiT trial. J Urol. 2010; 183: 1438-43.

40. Schreiner L, dos Santos TG, Knorst MR, da Silva Filho IG: Randomized trial of transcutaneous tibial nerve stimulation to treat urge urinary incontinence in older women. Int Urogynecol J. 2010; 21: 1065-70.

41. Sancaktar M, Ceyhan ST, Akyol I, Muhcu M, Alanbay I, Mutlu Ercan C, et al:: The outcome of adding peripheral neuromodulation (Stoller afferent neuro-stimulation) to anti-muscarinic therapy in womenwith severe overactive bladder. Gynecol Endocrinol. 2010; 26: 729-32.

42. Peters KM, Macdiarmid SA, Wooldridge LS, Leong FC, Shobeiri SA, Rovner ES, et al:: Randomized trial of percutaneous tibial nerve stimulation versus extended-release tolterodine: results from the overactivebladder innovative therapy trial. J Urol. 2009; 182: 1055-61.

43. Karademir K, Baykal K, Sen B, Senkul T, Iseri C, Erden D: A peripheric neuromodulation technique for curing detrusor overactivity: Stoller afferent neurostimulation. Scand J Urol Nephrol. 2005; 39: 230-3.

44. Finazzi Agrò E, Campagna A, Sciobica F, Petta F, Germani $S$, Zuccalà $A$, et al.: Posterior tibial nerve stimulation: is the once-a-week protocol the best option? Minerva Urol Nefrol. 2005; 57: 119-23.

45. Schmidt RA, Jonas U, Oleson KA, Janknegt RA, Hassouna MM, Siegel SW, et al.: Sacral nerve stimulation for treatment of refractory urinary urge incontinence. Sacral Nerve Stimulation Study Group.J Urol. 1999; 162: 352-7.

46. Hassouna MM, Siegel SW, Nÿeholt AA, Elhilali MM, van Kerrebroeck PE, Das AK, et al.: Sacral neuromodulation in the treatment of urgency-frequency symptoms: a multicenter study on efficacy and safety. J Urol. 2000; 163: 1849-54.

47. Kaya S, Akbayrak T, Beksaç S: Comparison of different treatment protocols in the treatment of idiopathic detrusor overactivity: a randomized controlledtrial.Clin Rehabil. 2011; 25: 327-38.

Correspondence address:

Dr. Lucas Schreiner

Avenida Ipiranga, 6690 / 612

Centro Clínico

Jardim Botânico, Porto Alegre, 90610-001, Brazil

Fax: +55 51 3320-5179

E-mail: schreinerlucas@hotmail.com 